Risk of major depressive disorder among older persons living in HIV-endemic central and southwestern Uganda

Eugene Kinyanda ${ }^{1,2,3}$, Monica Kuteesa ${ }^{1}$, Francien Scholten ${ }^{1}$, Joseph Mugisha ${ }^{1}$, Kathy Baisley $^{3}$, Janet Seeley ${ }^{1,3}$

${ }^{1}$ Medical Research Council/ Uganda Virus Research Institute, Entebbe, Uganda

${ }^{2}$ Department of Psychiatry, Makerere College of Health Sciences, Kampala Uganda

${ }^{3}$ London School of Hygiene and Tropical Medicine, London, United Kingdom

Address of correspondence:

Eugene Kinyanda, MRC/UVRI Uganda Research Unit on AIDS, P.O. Box 49 Entebbe, Uganda. Telephone: +256772410285; Email: Eugene.Kinyanda@mrcuganda.org 


\title{
Risk of major depressive disorder among older people living in HIV-endemic central and southwestern Uganda
}

\begin{abstract}
Major depressive disorder (MDD) is projected to become the second most common cause of disability by 2020 calling for a better understanding its antecedents across the lifespan and in diverse socio-cultural settings. In this paper we describe the risk factors of MDD among older people $(50$ years + ) living in HIV-endemic central and southwestern Uganda. A cross sectional study was undertaken among 471 respondents $(50$ years + ) participating in the Wellbeing of Older People's Study (WOPS) cohort of the MRC/UVRI Uganda research Unit on AIDS in Uganda. Participants were from 5 strata: HIV negative, HIV positive on ART, HIV positive not on ART, having an adult child on ART, and having an adult child who died of HIV. Overall MDD prevalence was 9.2\% (95\% CI 6.7-12.2\%) with a prevalence among males of $7.4 \%$ (95\% CI 4.0-12.3\%) and females of $10.3 \%$ (95\% CI 7.0-14.3\%). Factors significantly associated with MDD included: declining socio-economic status, increasing disability scores, decreasing mean grip strength, reported back pain, and not having hypertension. Marginally associated with MDD was being HIV infected and not on ART.
\end{abstract}

Keywords: major depressive disorder, older people, risk factors, HIV-endemic settings, Africa 


\section{Risk of major depressive disorder among older people living in HIV-endemic central and southwestern Uganda}

\section{BACKGROUND}

Major depressive disorder (MDD) is projected to become the second most common cause of disability by 2020 calling for a better understanding its antecedents across the lifespan and in diverse socio-cultural settings (Ustün et al, 2004). In this paper we describe the risk factors of MDD among older people (50 years +) living in HIV-endemic central and southwestern Uganda. Based on the stress-vulnerability model for depression (Monroe and Simon, 1991), we developed a conceptual framework (Figure 1) where we hypothesized that the stress factors of having medical complications of aging (Bosworth et al, 2003; Hamer et al, 2011), being HIV infected (Nakasujja, 2009; Llorente \& Malphurs, 2006) and HIV affected (having lost an adult child to HIV or having an adult child sick with HIV) (United Nations, 2002) acting on the vulnerability factors of disability (Clausen et al, 2005), poor social networks (Singh \& Misra, 2009) and poor hand grip strength (Lee et al, 2011; Fukumori et al, 2015) in a poor socio-economic context (Gureje et al, 2007) was associated with MDD.

We tested this hypothesis among older people participating in the Wellbeing of Older People's Study (WOPS) cohort of the MRC/UVRI Uganda Research Unit on AIDS (MRC/UVRI) in Uganda.

\section{METHODS}

Enrolled into this study was a sample of 471 older persons (50 years+) divided into five nearly equal strata: i) with an adult child who had died of AIDS; ii) with an adult child who was living with HIV and on ART; iii) had no child with HIV/AIDS and were not infected with HIV themselves (comparison 
group); iv) HIV infected and on ART for at least one year (initiation of ART was in accordance with 2011 Uganda MOH ART guidelines; Uganda MOH,2011); and v) HIV infected but not yet on ART. The composition and characteristics of this group are described elsewhere (Scholten et al, 2011; Mugisha et al, 2013).

\section{Variables collected}

1) Socio-demographic factors including a socio-economic status (SES) index that was constructed from ownership of 27 household assets using principle component analysis,_2) Psychosocial factors: i) $\underline{W H O}$ Disability scale (WHODAS scores) (WHO, 2014; Scholten et al, 2011); ii) Social Network Index (SNI) (Scholten et al, 2011); 3) Medical and psychiatric disorder: Self report on the following medical conditions: i) stiffness in the joints in the morning, ii) back pain during the last month, iii) whether had a known diabetic mellitus disorder, and iv) whether had blurred vision. Respondents were also assessed for the following: v) hypertension, defined as systolic blood pressure $\geq 140 \mathrm{mmHg}$ or diastolic blood pressure $\geq 90 \mathrm{mmHg}$, based on the average of three readings, or currently taking medication for hypertension, vii) $\underline{\text { hand grip strength was assessed using a Smedley's hand dynamometer, viii) presence of major depressive }}$ disorder (MDD) assessed using the MDD module of the M.I.N.I. neuropsychiatric interview (MINI Plus) which is a DSM IV based structured interview (Sheehan et al, 1998).

\section{Statistical Analysis}

We estimated odds ratios (OR) and 95\% confidence intervals (CI) for associations with MDD using logistic regression. Age and sex were included in all models as a priori confounders. Potential 
determinants of MDD were examined using the conceptual framework (Figure 1) with three levels: sociodemographic factors, psychosocial factors, and medical and psychiatric factors. The association with grip strength was also adjusted for BMI, as an a priori confounder.

\section{Ethical Issues}

The study sought and obtained science and ethical clearance from the Uganda Virus Research Institute's Science and Ethical Committee and the Uganda National Council for Science and Technology. Informed consent was sought from study participants.

\section{RESULTS}

Only data from 468 (99.4\%) respondents was used in this analysis (data from 3 respondents had incomplete MDD assessments, hence was not used). Characteristics of study respondents are shown in Table 1.

\section{Prevalence of major depressive disorder}

The prevalence of major depressive disorder (MDD) in this study was 9.2\% (95\% CI 6.7-12.2\%). The prevalence among males was 7.4\% (95\% CI 4.0-12.3\%) and among females $10.3 \%$ (95\% CI 7.0-14.3\%).

\section{Association between MDD and socio-demographic factors}

\section{Insert Table 1}


Table 1, after adjusting for age and sex, only SES index was significantly associated with MDD.

\section{Position for Table 2}

\section{Association between MDD and psychosocial and medical factors}

Table 2, after adjusting for age and sex, the only psychosocial factor significantly associated with MDD was WHODAS scores. There was some evidence of an association with study group, the highest prevalence of MDD was among those who were HIV positive not yet eligible for ART (20\%).

The medical factors significantly associated with MDD were grip strength and reported back pain. There was an inverse association with hypertension, with MDD prevalence among participants diagnosed with hypertension being significantly lower than that among those without hypertension.

\section{DISCUSSION:}

The prevalence of MDD in this study was $9.6 \%$, a rate slightly higher than that of $7 \%$ that was reported among older people in two community studies in Nigeria and Botswana (Gureje et al, 2010; Clausen and colleagues, 2005). These high rates of MDD among older people living in sub-Saharan Africa call for the integration of mental health care in older people's health care programs in sub-Saharan Africa. In this study, declining socio-economic status was significantly associated with increasing odds for MDD. In Nigeria, indices of socio-economic disadvantage (being widowed, separated or divorced) were found to be associated with MDD (Gureje et al, 2007). These findings point to the need to consider the socio-economically disadvantaged older 
people in sub-Saharan Africa as a risk group for MDD.

On psychosocial factors associated with MDD, only worsening disability scores was associated with increased odds of MDD. Studies undertaken elsewhere both in sub-Saharan Africa and in the west have shown a similar trend (Clausen et al, 2005; Prince et al, 1998). Since disability among older people has been associated with various medical and psychiatric problems, including MDD in this study, disability assessment should be incorporated in the routine clinical assessment of older people accessing care in sub-Saharan African settings. Study group was marginally associated with MDD with those who were HIV positive but not yet eligible for ART having the highest prevalence of MDD. This result suggests that HIV infection in older persons may be a risk factor for MDD as has been reported elsewhere (Nakasujja, 2009; Llorente \& Malphurs, 2006). Care programs for older people in sub-Saharan Africa should consider persons living with HIV as a risk group for MDD.

In this study, back pain was positively associated with MDD a finding that has been observed by other researchers both in sub-Saharan Africa and in the west (Gureje et al, 2010; Rudy et al, 2007). Orthopedic services for older people in sub-Saharan Africa should screen for MDD as a possible comorbidity. In this study decreasing mean grip strength was associated with increasing odds of having MDD, a trend which was observed on both hands. A similar trend has been reported by researchers elsewhere (Lee et al, 2011; Fukumori et al, 2015). Grip strength apart from being found to be associated with MDD in this study has previously been shown to be a good indicator of both frailty and mortality (Adedoyin et al, 2009; Guerra and Amaral, 2009), these associations and the fact that it is an easy variable to assess makes it a good candidate for 
inclusion in a screening package for psychological and medical problems of older people in the sub-Saharan African setting. In this study hypertension was inversely associated with MDD with those with hypertension having lower rates of MDD compared with those reporting no hypertension. In the literature, there has been conflicting reports on the association between blood pressure and depression, with Scalco and colleagues (2005) in a systematic review reporting evidence for a positive association between depression with both hypertension and hypotension. To obtain a more complete understanding of the relationship between blood pressure and MDD in the sub-Saharan Africa setting, there is need for more studies including investigating the relationship between MDD on one hand and hypotension and antihypertensive medication on the other.

Limitations, these include that, this study was not specifically powered to investigate the risk factors of MDD hence some of the marginal associations could have been due to insufficient study power. Secondly, because the absolute numbers with MDD were small, we could not adequately adjust for multiple confounders. Thirdly, 148 (29\%) of the initial cohort sample had been lost by the time of this second round of data collection (Mugisha et al, 2013), this could potentially have introduced bias into the study.

\section{CONCLUSION}

There is a considerable burden of MDD among older people living in the HIV-endemic setting of central and south-western Uganda. In agreement with the hypothesized conceptual framework, the stress factors of medical complications of aging and being HIV positive and not on ART, the vulnerability factor of disability and the contextual factor of poor socio-economic status were found to be associated with MDD in this study. 


\section{RECOMMENDATIONS}

There is a need to include mental health care in medical care programs of older people living in sub-

Saharan Africa regardless of HIV status. Secondly, care programs for older people should screen those who are HIV positive for mental health problems including MDD.

\section{REFERENCE}

Adedoyin, R.A., Ogundapo, F.A., Mbada, C.E., Adekanla, B.A., Johnson, O.E., Onigbinde, T.A., \& Emechete, A.A.I. (2009). Reference values for handgrip strength among healthy adults in Nigeria. Hong Kong Physiotherapy Journal, 27, 21-29.

Bosworth, H.B., Bartash, R.M., Olsen, M.K., \& Steffens, D.C. (2003). The association of psychosocial factors and depression with hypertension among older adults. International Journal of Geriatric Psychiatry, 18(12), 1142-8.

Clausen, T., Romøren, T.I., Ferreira, M., Kristensen, P., Ingstad, B., \& Holmboe-Ottesen, G. (2005). Chronic diseases and health inequalities in older persons in Botswana (southern Africa): a national survey. Journal of Nutrition, Health \& Aging, 9(6), 455-61.

Dayton, J., \& Ainsworth, M. (2004). The elderly and AIDS: coping with the impact of adult death in Tanzania. Social Science \& Medicine, 59(10), 2161-72. 30.

Fiske, A., Wetherell, J.L., \& Margaret Gatz M. (2009). Depression in older adults. Annual Review of Clinical Psychology, 5, 363-389.

Fukumori, N., Yamamoto, Y., Takegami, M., Yamazaki, S., Onishi, Y., Sekiguchi, M., Otani, 
K., Konno, S., Kikuchi, S., \& Fukuhara, S. (2015). Association between hand-grip strength and depressive symptoms: Locomotive Syndrome and Health Outcomes in Aizu Cohort Study (LOHAS). Age Ageing, 44(4), 592-8.

Guerra, R.S., \& Amaral, T.F. (2009). Comparison of hand dynamometers in elderly people. Journal of Nutrition, Health \& Aging, 13(10), 907-12.

Gureje, O., Kola, L., \& Afolabi, E. (2007). Epidemiology of major depressive disorder in elderly Nigerians in the Ibadan Study of Ageing: a community-based survey. Lancet, 370 (9591), 957-64.

Gureje, O., Uwakwe, R., Oladeji, B., Makanjuola, V.O., \& Esan, O. (2010). Depression in adult Nigerians: results from the Nigerian Survey of Mental Health and Well-being. Journal of Affective Disorders, 120(1-3), 158-64.

Hamer, M., Malan, N.T., Harvey, B.H., \& Malan, L. (2011). Depressive symptoms and subclinical atherosclerosis in Africans: role of metabolic syndrome, inflammation and sympathoadrenal function. Physiology \& Behavior Journal, 104(5), 744-8.

Hosegood, V., Timaeus, I.M. (2006). HIV/AIDS and older people in South Africa. National Research Council (US) Committee on Population; Cohen B, Menken J, editors. Washington (DC): National Academies Press (US). http://www.ncbi.nlm.nih.gov/books/NBK20298/.

Lee, A.L., Herbert, A.W., \& Lachman, M.E. (2011). Age differences in the relationship of hand grip strength and depression. A poster presented at the Annual Meeting of the Eastern Psychological Association, Cambridge, MA, March 2011. http://www.brandeis.edu/departments/psych/lachman/pdfs/EPA\%202011.pdf

Knodel, J., Watkins, S., \& VanLandingham, M. (2003). AIDS and older persons: an International perspective. Journal of Acquired Immune Deficiency Syndromes, 33 (Suppl 
2), S153-65.

Kowal, P., Kahn, K., Ng, N., Naidoo, N., Abdullah, S., Bawah, A., Binka, F., Chuc, N.T., et al. (2010). Ageing and adult health status in eight lower-income countries: the INDEPTH WHO-SAGE collaboration. Global Health Action, 3. doi: 10.3402/gha.v3i0.5302.

Llorente, M., \& Malphurs, J. (2006) HIV/AIDS among older adults. In F.F.Ruiz (Ed), Psychiatric aspects of HIV/AIDS (pp. 267-276). Philadelphia: Williams and Wilkins.

Ministry of Health, Uganda. (2011). The integrated national guidelines on antiretroviral therapy, prevention of mother to child transmission of HIV and infant and young child feeding.

http://www.sustainuganda.org/content/integrated-national-guidelines-art-pmtct-and-iycf-2012

Monroe, S.M., \& Simon, A.D. (1991). Diathesis-stress theories in the context of life stress research: implications for the depressive disorders. Psychological Bulletin, 110:406-425.

Mugisha, J., Scholten, F., Owilla, S., Naidoo, N., Seeley, J., Chatterji, S., Kowal, P., \& Boerma, T. (2013). Caregiving responsibilities and burden among older people by HIV status and other determinants in Uganda. AIDS Care, 25(11), 1341-8.14.

Nakasujja, N. (2009). HIV/AIDs in old age. In S. Musisi \& E. Kinyanda (Eds ) Psychiatric problems of HIV/AIDS and their management in Africa (pp. 183-192). Kampala: Fountain Publisher.

Oburu, P.O., \& Palmérus, K. (2005). Stress related factors among primary and part-time caregiving grandmothers of Kenyan grandchildren. International Journal of Aging \& Human Development, 60(4), 273-82.

Prince, M.J., Harwood, R.H., Thomas, A., \& Mann, A.H. (1998). A prospective populationbased cohort study of the effects of disablement and social milieu on the onset and maintenance of late-life depression. The Gospel Oak Project VII. Psychological Medicine, 
28(2), 337-50.

Rudy, T.E., Weiner, D.K., Lieber, S.J., Slaboda, J., \& Boston, J.R. (2007). The impact of chronic low back pain on older adults: a comparative study of patients and controls. Pain, 131(3), 293-301.

Scalco, A.Z., Scalco, M.Z., Azul, J.B., \& Lotufo Neto F. (2005). Hypertension and depression. Clinics (Sao Paulo), 60(3), 241-50.

Scholten, F., Mugisha, J., Seeley, J., Kinyanda, E., Nakubukwa, S., Kowal, P., Naidoo, N., Boerma, T, Chatterji, S., \& Grosskurth, H. (2011). Health and functional status among older people with HIV/AIDS in Uganda. BMC Public Health, 11(1), 886.

Sheehan, D.V., Lecrubier, Y., Sheehan, K.H., Amorim, P., Janavs, J., Weiller, E., Hergueta, T., Baker, R., \& Dunbar, G.C. (1998). The Mini-International Neuropsychiatric Interview (M.I.N.I.): the development and validation of a structured diagnostic psychiatric interview for DSM-IV and ICD-10. Journal of Clinical Psychiatry, 59(Suppl 20), 22-33.

Singh, A., \& Misra, N. (2009). Loneliness, depression and sociability in old age. Indian Psychiatry Journal, 18(1): 51-55.

Ssengonzi, R. (2009). The impact of HIV/AIDS on the living arrangements and well-being of elderly caregivers in rural Uganda. AIDS Care, 21(3), 309-14.

United Nations. (2002). HIV/AIDS and older people. http://www.globalaging.org/waa2/articles/hivolder.htm

World Health Organisation. (2014). WHO Disability Assessment Schedule 2.0 (WHODAS 2.0). http://www.who.int/classifications/icf/whodasii/en/ 
Table I. Association of current major depressive disorder with sociodemographic factors

\begin{tabular}{|c|c|c|c|}
\hline & n with depression / tot & $\begin{array}{c}\text { crude Odds Ratio } \\
\qquad(95 \% \mathrm{Cl})\end{array}$ & adjusted Odds Ratio ${ }^{1}$ ( 9 \\
\hline Sex & & $P=0.29$ & $P=0.31$ \\
\hline Male & 13 / 176 (7.4\%) & 1 & 1 \\
\hline Female & 30 / 292 (10.3\% & $1.44(0.73-2.83)$ & $1.41(0.71-2.78)$ \\
\hline \multicolumn{4}{|l|}{ Age } \\
\hline 50-59 years & 21 / 167 (12.6\% & $P=0.06$ & $P=0.06$ \\
\hline $60-69$ years & 13 / 152 (8.6\%) & $0.73(0.52-1.02)^{:}$ & $0.73(0.52-1.03)$ \\
\hline $70+$ years & 9 / 149 (6.0\%) & & \\
\hline Education level & & $P=0.35$ & $P=0.24$ \\
\hline Secondary or higher & $6 / 112(5.4 \%)$ & 1 & 1 \\
\hline Completed primary & 5 / 58 (8.6\%) & $1.67(0.49-5.71)$ & $1.40(0.40-4.85)$ \\
\hline Incomplete primary & 23 / 208 (11.1\% & $2.20(0.87-5.56)$ & $2.41(0.94-6.18)$ \\
\hline None & 9 / 87 (10.3\%) & $2.04(0.70-5.96)$ & $2.17(0.72-6.53)$ \\
\hline Salary earner in household? & & $P=0.26$ & $P=0.24$ \\
\hline Yes & 2 / 42 (4.8\%) & 1 & 1 \\
\hline No & 41 / 426 (9.6\%) & $2.13(0.50-9.14)$ & $2.20(0.51-9.56)$ \\
\hline Marital status & & $P=0.60$ & $P=0.90$ \\
\hline Married & 12 / 147 (8.2\%) & 1 & 1 \\
\hline Not married & 31 / 321 (9.7\%) & $1.20(0.60-2.41)$ & $1.05(0.46-2.40)$ \\
\hline Socioeconomic status & & $P=0.02$ & $P=0.02$ \\
\hline Top tertile & 7 / 156 (4.5\%) & 1 & 1 \\
\hline Middle tertile & 15 / 157 (9.6\%) & $2.25(0.89-5.68)$ & $2.23(0.88-5.65)$ \\
\hline Bottom tertile & $21 / 155$ (13.5\% & $3.34(1.37-8.10)$ & $3.19(1.31-7.76)$ \\
\hline
\end{tabular}

${ }^{1}$ Adjusted for age (as a continuous covariate) and sex a priori. ${ }^{2}$ Odds ratio for linear trend in odds of MDD with 10 year increase in age. 
Table II. Association of current major depressive disorder with psychosocial and medical factors

\begin{tabular}{|c|c|c|c|}
\hline & $\begin{array}{c}\text { n with depression / } \\
\text { (\%) }\end{array}$ & $\begin{array}{l}\text { crude Odds Ratio } \\
(95 \% \mathrm{Cl})\end{array}$ & adjusted Odds Ratio ${ }^{1}$ (9) \\
\hline \multicolumn{4}{|l|}{ Psychosocial factors } \\
\hline Social network index & & $P=0.59$ & $\mathrm{P}=0.46$ \\
\hline High (score 3 or 4 ) & $13 / 170(7.6 \%$ & 1 & 1 \\
\hline Middle (score 2) & $14 / 153$ (9.29 & $1.22(0.55-2.68)$ & $1.27(0.57-2.81)$ \\
\hline Low (score 0 or 1 ) & $16 / 145$ (11.0 & $1.50(0.69-3.23)$ & $1.66(0.75-3.67)$ \\
\hline \multicolumn{4}{|l|}{ WHODAS score $(\%)^{2}$} \\
\hline Bottom tertile $(<6 \%)$ & 9 / 162 (5.6\% & $P<0.001$ & $\mathrm{P}<0.001$ \\
\hline Middle tertile (6-<37\%) & 13 / 157 (8.3\% & $1.23(1.09-1.39)^{3}$ & $1.37(1.19-1.59)^{3}$ \\
\hline Top tertile $(\geq 37 \%)$ & $21 / 149(14.1$ & & \\
\hline \multicolumn{4}{|l|}{ Medical factors } \\
\hline Study group & & $P=0.02$ & $P=0.07$ \\
\hline HIV negative, not affected & $5 / 70$ (7.1\% & 1 & 1 \\
\hline HIV positive on ART & 19 / 194 (9.8 & $1.41(0.51-3.94)$ & $1.06(0.34-3.30)$ \\
\hline HIV pos not eligible for ART & $10 / 50\left(20.0^{\circ}\right.$ & $3.25(1.04-10.20)$ & $2.49(0.75-8.32)$ \\
\hline Adult child on ART & 2 / $76(2.6 \%$ & $0.35(0.07-1.87)$ & $0.32(0.06-1.72)$ \\
\hline Adult child died of HIV & $7 / 78$ (9.0\% & $1.28(0.39-4.24)$ & $1.21(0.36-4.03)$ \\
\hline Stiffness in joints in morning & & $P=0.25$ & $\mathrm{P}=0.18$ \\
\hline No & $26 / 320(8.19$ & 1 & 1 \\
\hline Yes & $17 / 148(11.5$ & $1.47(0.77-2.80)$ & $1.59(0.81-3.09)$ \\
\hline Back pain in last month & & $P=0.05$ & $P=0.03$ \\
\hline No & $11 / 183$ (6.0 & 1 & 1 \\
\hline Yes & $32 / 283$ (11.3 & $1.99(0.98-4.06)$ & $2.22(1.07-4.62)$ \\
\hline Hypertension ${ }^{4}$ & & $P=0.006$ & $P=0.01$ \\
\hline No & 35 / 294 (11.9' & 1 & 1 \\
\hline Yes & $8 / 174(4.6 \%$ & $0.36(0.16-0.79)$ & $0.38(0.17-0.84)$ \\
\hline Previous diagnosis of diabetes & & $P=0.18$ & $\mathrm{P}=0.16$ \\
\hline No & $39 / 444\left(8.8^{\circ}\right.$ & 1 & 1 \\
\hline Yes & 4 / $22(18.2 \%$ & $2.31(0.74-7.16)$ & $2.43(0.76-7.73)$ \\
\hline Cloudy/blurry vision & & $P=0.17$ & $P=0.10$ \\
\hline No & 7 / 114 (6.1\% & 1 & 1 \\
\hline Yes & $36 / 350(10.3$ & $1.75(0.76-4.05)$ & $1.97(0.84-4.62)$ \\
\hline \multicolumn{4}{|l|}{ Mean grip strength (left) } \\
\hline Top tertile & 7 / 148 (4.7\% & $P<0.001$ & $P<0.001$ \\
\hline Middle tertile & 12 / 153 (7.8? & $1.47(1.18-1.82)^{5}$ & $1.83(1.36-2.45)^{5,4}$ \\
\hline Bottom tertile & $24 / 157$ (15.3 & & \\
\hline \multicolumn{4}{|l|}{ Mean grip strength (right) } \\
\hline Top tertile & $10 / 150$ (6.7\% & $P<0.001$ & $\mathrm{P}<0.001$ \\
\hline Middle tertile & $8 / 143(5.6 \%$ & $1.43(1.15-1.78)^{5}$ & $1.81(1.33-2.47)^{5, \mathrm{~g}}$ \\
\hline Bottom tertile & 24 / 157 (15.3' & & \\
\hline
\end{tabular}


Mean grip strength (both)

Top tertile

$8 / 153$ (5.2\%

$\mathrm{P}<0.001$

$\mathrm{P}<0.001$

Middle tertile

13 / 149 (8.79

$1.50(1.20-1.88)^{5}$

$1.98(1.44-2.73)^{5}$

Bottom tertile

$22 / 155(14.2$

${ }^{1}$ Adjusted for age (as a continuous covariate) and sex a priori. ${ }^{2}$ Calculated from 9 items in 5 domains; total possible score out of $36 .{ }^{3}$ Odds ratio for linear trend in odds of MDD with 10 point increase in WHODAS score. ${ }^{4}$ Systolic blood pressure $\geq 140 \mathrm{mmHg}$ and/or diastolic blood pressure $\geq 90 \mathrm{mmHg}$, or taking medication for hypertension. ${ }^{5}$ Odds ratio for linear trend in odds of MDD with 5 unit decrease in mean grip strength. ${ }^{6}$ Adjusted for age, sex and BMI. 